\title{
POR UMA POLÍTICA DA DIFERENÇA
}

\author{
ELIZABETH MACEDO \\ Faculdade de Educação da Universidade do Estado do Rio de Janeiro \\ elizabethmacedo@gmail.com
}

\begin{abstract}
RESUMO
O artigo defende que a educação, para fazer face às sociedades multiculturais, precisa pensar a cultura como lugar de enunciação e não como repertório de sentidos partilhados. Inicialmente, analisa os projetos conservadores, liberais e multiculturais para lidar com a diferença cultural, argumentando que esses projetos tratam a diferença como diversidade, não conseguindo, dessa forma, responder, como se propõem às demandas de uma sociedade multicultural. Para além desses projetos, discute perspectivas de tradução e diálogo entre culturas, valendo-se, principalmente, das contribuições de Santos e Burbules, concluindo pela incomensurabilidade das culturas. Ainda que as culturas sejam incomensuráveis, a autora rechaça descrições fragmentadas da contemporaneidade, posicionando-se em favor da negociação da diferença cultural. Para isso, apóia-se na noção de ambivalência de Bhabha e na noção de hegemonia, tal como é defendida por Laclau e Mouffe, Hall e pelo próprio Bhabha. Dessa forma, procura estabelecer uma agenda pós-colonial para pensar a diferença. POLÍTICAS EDUCACIONAIS - MULTICULTURAL - CULTURA - EDUCAÇÃO
\end{abstract}

\section{ABSTRACT}

FOR A POLICY TO DEAL WITH DIFFERENCES. This work advocates that, in order to face multicultural societies, it is necessary for education to think culture as a place of enunciation and not just as a repertoire of shared meanings. It starts by analyzing conservative, liberal and multicultural projects dealing with cultural difference, arguing that since they consider difference as diversity, they are not able answer, as intended, to the demands of a multicultural society. Besides these projects, this article also analyzes perspectives on translation and dialogue between cultures, relaying mainly on the contributions of Santos and Burbules. Thus, the present work acknowledges the incommensurability of cultures but refutes present-day

Texto produzido a partir de discussões da pesquisa Currículo de Ciências: uma abordagem cultural, financiada pelo Conselho Nacional de Desenvolvimento Científico e Tecnológico - CNPq -, Fundação de Amparo à Pesquisa do Estado do Rio de Janeiro - Faperj - e Programa Prociência da Universidade Estadual do Rio de Janeiro - Uerj. 
fragmented descriptions, taking sides in favor of negotiating the question of cultural difference. With such purpose, Bhabha's notion of ambivalence, as well as that of homogeneity, advocated by Laclau and Mouffe, Hall and Bhabha himself, is put forward. In this way, it tries to build a postcolonial agenda for thinking the difference.

EDUCATIONAL POLICIES - MULTICULTURALISM - CULTURE - EDUCATION

Temos presenciado no Brasil, ultimamente, uma ampliação do debate sobre ações afirmativas na esteira da política de cotas para ingresso tanto nas universidades públicas quanto em empregos conquistados por concurso. Trata-se da mais nova conseqüência da ação do movimento negro legitimada, segundo Guimarães (2005), pela incapacidade da diplomacia brasileira de convencer os foros internacionais da inexistência de uma questão racial no Brasil. $\bigcirc$ paradigma da convivência pacífica entre as culturas, que apresenta o Brasil como um país mestiço, vem sendo superado paulatinamente. Embora a luta pelas cotas seja apenas uma das muitas áreas em que o movimento negro atuou nos últimos anos - divulgação da cultura e religiosidades negras, educação básica, direitos humanos, saúde pública, sexualidade, cursos pré-vestibulares -, sua visibilidade trouxe para o centro do debate questões multiculturais que sempre estiveram pouco presentes nas discussões sobre políticas educacionais do país. Ainda que seja necessário salientar todo o esforço de parte da sociedade para tirar das cotas seu caráter racial - incluindo, por exemplo, classe social, renda familiar ou formação em escola pública -, a política de cotas respondeu de alguma forma ao movimento negro e tornou mais visível a existência de demandas étnico-raciais no país.

Não é simples discutir o multiculturalismo nas políticas educacionais, porque, ainda que o termo seja utilizado na maioria dos países, seus significados discursivos deslizam em um terreno pantanoso. Como salienta Hall (2003), este termo "só pode ser utilizado 'sob rasura'" (p.5I). Vou me valer neste artigo de uma distinção que tanto Hall (2003) quanto Santos e Nunes (2003) utilizam, e que no meu entender permite elucidar algumas das confusões que o termo comporta. Refiro-me à distinção entre multiculturalismo "como descrição" e "como projeto", como explicitam Santos e Nunes. Ou, nas palavras de Hall, entre multicultural como termo qualificativo e multiculturalismo como doutrina política.

Quando falam em multiculturalismo como descrição ou em multicultural como termo qualificativo, os autores estão tratando de algo que não é novo. 
Sociedades multiculturais sempre existiram, desde as primeiras diásporas com migrações de povos (e, portanto, de culturas), causadas por tragédias naturais ou por motivos políticos e religiosos, e constituem "as condições de definição sócio-histórica da humanidade" (Goldberg apud Hall, 2003, p.55). Esse caráter multicultural das sociedades teve momentos de intensificação, como nas conquistas que geraram os grandes impérios ou nas Grandes Navegações européias, ou na internacionalização capitalista. Mais recentemente, além dos fluxos migratórios do capitalismo transnacional, poderíamos considerar ainda a interação cultural provocada pela ampliação do contato virtual entre as culturas. Se, por um lado, os contatos interculturais se intensificaram graças ao desenvolvimento tecnológico, por outro, a acentuação do caráter multicultural das sociedades contemporâneas deve-se em grande parte à contestação de comunidades imaginadas hegemônicas na Modernidade.

Ainda que os homens sempre tenham migrado, é muito comum, ao longo da história, que esses encontros de culturas diversas tenham sido marcados pela construção de ilusões de homogeneidade, quer por uma suposta assimilação do diferente, quer por sua exclusão na figura do "outro". As idéias de nação e de Estado Moderno foram talvez os mais poderosos instrumentos dessa construção, criando a ilusão de pertencimento pela via do nascimento que, segundo Bauman (2005), como nada tinha de natural, precisava ser garantida pela coerção e pelo convencimento. A manutenção da ilusão dependia de um projeto capaz de fazer com que um coletivo chamado nação se sobrepusesse aos interesses individuais dos sujeitos, o que foi garantido pela "superposição do território domiciliar com a soberania indivisível do Estado" (p.27), cuja principal tarefa era a exclusão de tudo aquilo que pudesse pôr em risco o projeto coletivo. Tarefa que, para Bauman, o Estado Moderno cumpriu com maestria, construindo uma identidade nacional que exigia exclusividade e estabelecendo para si a função de árbitro máximo sobre as identidades que seriam toleradas. Outras identidades somente seriam aceitas se não pusessem em jogo a supremacia da identidade nacional, o que garantia ao Estado um certo poder de certificação dos demais pertencimentos.

A análise de Santos (1997), tanto do Estado liberal quanto do projeto marxista, corrobora a leitura de Bauman. Para o autor, embora o sujeito moderno, do liberalismo ao marxismo, apresente inúmeras variantes, poderíamos considerar que há algo que partilham: a subsunção das identidades à identida- 
de global do Estado e a "uma identidade simétrica do Estado, global e idêntica a ele - a sociedade" (p. I43). Assim, Santos também avalia que todas as demais identidades foram incorporadas numa identidade una, fixa e supostamente partilhada por todos, a identidade nacional.

A centralidade do Estado em nossa constituição identitária como sujeitos da Modernidade é visível, inclusive quando a ênfase está nos movimentos reivindicatórios de identidades particulares. No recente debate sobre cotas raciais, foi freqüente a menção a uma característica própria do Brasil, onde as relações raciais seriam harmônicas, em contraposição à realidade americana. A crítica às políticas afirmativas foi feita, portanto, tendo por base um pertencimento nacional de certa forma naturalizado. Além disso, a própria terminologia utilizada para nomear identidades raciais acaba por remeter à idéia de nação (afro-brasileiros) assim como outras formas de organização social, por exemplo, indígenas, são nomeadas pelo epíteto de "nação" - nação ianomâmi.

Se a idéia de nação e a concepção de Estado tiveram e têm ainda um importante papel no apagamento ou na subsunção de outras identidades, é também perceptível um certo esgotamento de seu potencial de ação. Esse esgotamento, com o afloramento de tensões entre as diferentes culturas que convivem num inventado espaço nacional, tem feito com que passemos a perceber as sociedades em que vivemos como multiculturais. Definir o que tem produzido tal impacto sobre os Estados nacionais não é, no entanto, tarefa fácil. É verdade que a nova fase do capitalismo, muito mais global, tem limitado o poder dos Estados nacionais com uma nova configuração geopolítica em que blocos econômicos alteram, de alguma forma, as antigas soberanias nacionais. Mas é também verdade que todas essas alterações têm sido feitas dentro de uma moldura em que ainda há lugar para os Estados nacionais.

Para autores pós-coloniais, o questionamento da idéia de nação é produto principalmente das lutas pela libertação das colônias, que tiveram forte influência sobre a forma como a nação foi teorizada. Chaterjee (2000) faz uma das mais amplas discussões pós-coloniais da idéia de nação, associando-a aos processos históricos de industrialização e democratização da Europa. Por tal associação, as nações surgiram para perseguir os valores universais do lluminismo europeu, tais como liberdade e progresso. A despeito de propagar esses ideais de liberdade e progresso, a manutenção da idéia de nação dependeu historicamente de uma certa cumplicidade com formas autoritárias 
de governo e, especialmente, com a expansão colonial. Essa controvérsia, Chaterjee chamou de dilema liberal. Um dilema que desnuda o fato de que a idéia de nação é uma idéia européia que passou por cima das etnicidades e das diferenças culturais. Se isso permanecia pouco visível ao se tratar da Europa e mesmo de países cujas colonizações políticas terminaram por volta da Revolução Francesa, tornava-se evidente ao se observar a situação de países colonizados ainda na metade do século $X X$.

Na mesma linha pós-colonial, Bhabha (2003) argumenta que o fracasso da pretensão universalista da idéia de nação se deve ao fato de se tratar de uma representação frágil e instável, incapaz de garantir a unidade prometida. Há nos discursos sobre a nação uma ambivalência, produto da articulação de dois modos de representação contraditórios. Os discursos modernos, que buscaram instituir a nação como comunidade imaginada, articularam duas temporalidades distintas - uma continuísta e pedagógica e a outra performática -, tornando a nação cindida entre dois opostos incompatíveis: a nação como uma essência fixa originária e como algo socialmente construído. Se a temporalidade continuísta garante a homogeneidade na medida em que faz referência a um passado comum, a sempre necessária ação performática permite que os subalternos intervenham no processo de significação e alterem as representações dominantes. Ou seja, na concepção de Bhabha, a nação jamais conseguiu ou conseguirá banir a diferença, uma vez que as contranarrativas irrompem no nível performático.

Hall (2003) traça um quadro histórico do ressurgimento das sociedades multiculturais, associando-o tanto ao fenômeno pós-colonial como à globalização e à ampliação da utilização dos princípios de mercado. Para o autor, a distribuição desigual de poder e as relações de exploração que caracterizaram as sociedades coloniais permanecem na relação entre as nações e entre os grupos dentro de um mesmo Estado nacional. A globalização, mais fortemente sentida a partir da segunda metade do século passado, se fez de forma estruturalmente desigual, com franca dominância do que convencionalmente chamamos Primeiro Mundo, mantendo um sistema assimétrico semelhante ao vivido em situações de colonialismo político. Também o fim da Guerra Fria teve efeitos fortes na assimetria entre países e grupos dentro dos países. Hall lembra que princípios como o mercado foram apresentados de forma abstrata, "sem considerar o envolvimento cultural, político, social e institucional que os mercados 
sempre requerem" (p.57); no entanto, os problemas do desenvolvimento não são vividos de forma semelhante por todo o planeta. Em resumo, o autor argumenta que a globalização, por se assentar sobre a desigualdade, embora proponha como tendência cultural dominante a homogeneidade, não pode "controlar ou saturar tudo dentro de sua órbita" (p.59). Nesse sentido, surgem formações subalternas, com suas contranarrativas nas palavras de Bhabha.

Tanto as leituras pós-coloniais de Hall, Bhabha e Chaterjee como as explicações que relacionam o esgotamento da idéia de nação com a globalização e o maior desenvolvimento tecnológico são insuficientes para dar conta de algumas questões que permanecem inquietantes: se a idéia de nação é em si tão ambígua, tão frágil como princípio articulador da igualdade, como se sobrepôs por tanto tempo às particularidades, às etnicidades, às diferenças? Por que as contranarrativas, as representações marginais não deram conta de superar a hegemonia da combinação entre Estado e nação? Por que agora essas representações parecem ganhar terreno? E por que isso ocorre num momento em que a própria idéia de mercado é apresentada como universal inquestionável?

Não tenho a pretensão de responder a tais questões neste artigo. Apresento-as com um objetivo bem mais modesto, qual seja, deixar claro que não busco entender por que ressurgem preocupações multiculturais, mas apenas chamo a atenção para o fato de que vivemos num momento em que essas preocupações estão na ordem do dia. Os sólidos princípios que pareciam vincular um sujeito ao seu lugar de nascimento estão se liquefazendo, como descreve Bauman (2005). As estruturas e instituições sociais, muitas das quais sustentavam a idéia de nação, se tornaram fluidas. Nas palavras do autor, não se pode esperar "que a sociedade seja um árbitro das tentativas e erros dos seres humanos (...) de quem se espera ser justos e de princípios" (p.58). Sem árbitro, as diferenças ganham uma dimensão que se ocultava sob os consensos inventados. As tradições que irrompiam na Modernidade em formas marginais já não têm mais um padrão que as empurre para fora do centro. Coabitam com outras tradições tentando "construir uma vida em comum ao mesmo tempo em que retêm algo de sua identidade 'original'" (Hall, 2003, p.52).

Ao fato de que as sociedades sejam vistas como multiculturais tem correspondido, nas últimas décadas, o surgimento do multiculturalismo como projeto ou como doutrina política. O sem-número de adjetivações que acompanham o termo multiculturalismo - que vão desde liberal e emancipatório tal como utilizado por McLaren ( 1997 ) até, por exemplo, corporativo ou empre- 
sarial - já dão conta do fato de que nem todas as soluções políticas para uma sociedade multicultural são progressistas. Na definição de Hall (2003), o multiculturalismo pode ser visto como "estratégias e políticas adotadas para governar ou administrar problemas de diversidade e multiplicidade gerados pelas sociedades multiculturais" (p.52). Da mesma forma que o termo pode estar associado a projetos contra-hegemônicos e emancipatórios, não se pode negligenciar sua utilização para fazer referência a formas de regular e controlar a diferença. Iniciativas de discriminação positiva, assim como movimentos que lutam por uma política de identidade, dividem espaço na arena dos projetos multiculturais com programas assistenciais e/ou compensatórios que visam domesticar a diferença. Não são poucos, por exemplo, os projetos que se apresentam como apolíticos, ou que, sendo políticos, se inserem nas reivindicações de Estados nacionais, atribuindo status diferenciado a determinados grupos. No caso do Brasil, como lembra Guimarães (2005), as políticas multiculturais ainda lutam contra o mito de que se trata de um país mestiço em que as políticas sociais não devem priorizar grupos étnicos, mas visar toda a população.

Sem pretender estabelecer uma classificação exaustiva dos projetos multiculturais, até porque seria uma insensatez, na medida em que todos os projetos são eles mesmos híbridos de sentidos, passo a discutir alguns deles. Sustento que, embora eles surjam como resposta ao caráter multicultural da sociedade, tendem a fixar a diferença transformando-a em diversidade. Com isso, acabam por não dar conta de atender aos anseios que se propõem a responder. Não quero com isso desqualificar soluções multiculturais que vêm sendo criadas para lidar com propostas discriminatórias. Entendo, como Spivak (1994), que, embora algumas categorias que fixam a diferença não se sustentem do ponto de vista teórico, foram até agora as únicas possibilidades com as quais pudemos construir políticas antidiscriminação.

\section{OS PROJETOS MULTICULTURAIS}

Muitos são os autores (McLaren, 1997; McCarthy, 1994; Santos, Nunes, 2003; Hall, 2003) que vêm criando alguma sistemática para a análise dos projetos multiculturais, havendo aproximações, mas também divergências, entre eles. De modo geral, a maioria das tipologias propostas dá conta da existência de projetos conservadores, liberais e de outros que poderiam mais propriamente ser chamados de multiculturais. Para além desses projetos, os autores 
têm apresentado propostas do que, em linhas gerais, identifica-se como multiculturalismo crítico. Para McLaren ( 1997) e McCarthy (1994), por exemplo, a principal tarefa de um multiculturalismo crítico seria examinar a construção tanto da diferença quanto da identidade, contrapondo-se a projetos que não consideram a historicidade dessas diferenças. Apesar de defenderem que a negociação cultural não se dá num terreno sem contestação, sendo forjada em "esferas culturais incomensuráveis e assimétricas" (Mohanty, apud McLaren, 1997, p. 125), os autores explicitam pouco as formas como concebem projetos multiculturais críticos. Trazem, no entanto, uma importante contribuição quando advogam que uma agenda multicultural precisa superar os projetos conservadores, liberais e mesmo multiculturais vigentes. Precisa, como propõe Hall (2003), enfocar "o poder, o privilégio, a hierarquia de opressões e os movimentos de resistência" (p.53), de modo a reconstruir os sistemas em que as diferenças são construídas. É essa contribuição que pretendo desenvolver neste artigo, pensando um projeto alternativo para tratar a diferença. Antes, porém, julgo relevante um panorama sintético dos projetos em curso para que possamos perceber como, apesar de propalada, a diferença se mantém fora das agendas multiculturais.

Usarei para esse panorama, especialmente, as classificações de McLaren ( 1997), Santos e Nunes (2003) e McCarthy (1994). McLaren, cuja tipologia tem sido muito utilizada nas discussões sobre multiculturalismo no Brasil (Candau, 2005; Moreira, 1999; Moreira, Canen, 200 I), salienta que o trabalho que empreende é apenas um recurso heurístico, uma "tentativa inicial de transcodificar e mapear o campo cultural de raça e etnicidade" (p. I | 0). Julgo que podemos entender tanto as tipologias que usarei neste artigo quanto o uso que farei delas, fugindo assim da perspectiva positivista de que toda classificação implica classes mutuamente exclusivas e tipos puros. Ao contrário, construo o texto com a crença de que os projetos concretos para lidar com uma sociedade multicultural, em geral, articulam e hibridizam características conservadoras, liberais e multiculturais propriamente ditas.

As propostas conservadoras podem ser caracterizadas como aquelas que negam a descrição multicultural (Santos, Nunes, 2003), ou que, apesar de não negá-la, defendem uma cultura comum padrão (McLaren, 1997). De forma geral, os conservadores se contrapõem tanto aos programas de discriminação positiva quanto às alterações nos currículos escolares visando criar uma zona 
de visibilidade sobre as culturas das minorias. Vêem as culturas de grupos minoritários como manifestações inferiores que deveriam ser abolidas por um projeto educacional que visa a igualdade. Criticam, portanto, qualquer política identitária baseada na diferença e propõem a sua assimilação às tradições da maioria. As propostas conservadoras produzem uma ideologia da assimilação, pela qual pretendem que jovens de culturas minoritárias passem a participar da cultura iluminista como se fosse sua.

Stam (apud Santos, Nunes, 2003) resume as muitas críticas que os conservadores têm feito aos projetos multiculturais. Salienta que, para eles, esses projetos buscam promover a substituição de valores ocidentais por culturas inferiores e fragmentam a sociedade, pondo em risco o sentido de nação, cuja pureza e integridade são ressaltadas. $\bigcirc$ autor destaca, ainda, que a crítica conservadora vê o multiculturalismo como uma imposição de uma linguagem politicamente correta e como uma estratégia para aumentar a auto-estima de grupos minoritários que têm desempenho inferior não apenas na escola, mas em outras esferas sociais. Portanto, longe de questionar regimes de verdades racistas, o multiculturalismo conservador baseia-se em preconceitos e os reforça ao defender a valorização de padrões de desempenho claramente vinculados às culturas hegemônicas.

Classicamente, os projetos educacionais conservadores alicerçaram-se na naturalização da diferença, especialmente tendo em conta distinções biológicas entre os grupos. No que diz respeito à raça, por exemplo, muitos foram os estudos que buscaram mostrar a inferioridade de sujeitos não-brancos e construíram suas propostas educativas baseadas nessa inferioridade. Se é possível dizer que, atualmente, essas propostas são pouco expressivas, há resquícios do projeto conservador em muitas manifestações. No recente debate sobre cotas na universidade, alguns desses indícios ficaram claros. Podemos destacar a insistência com que as cotas são relacionadas a uma diminuição do rendimento como parte da agenda conservadora que sempre se pautou por uma suposta diferença em medidas psicométricas dos grupos raciais'. Também

I. Além disso, a resposta a essas críticas vem, muitas vezes, de grupos engajados nas políticas de ação afirmativa pela explicitação de que não há diferenças de rendimento entre cotistas e não cotistas nas universidades. Nesse sentido, embora questionem a correlação estabelecida pelos críticos conservadores, acabam por sustentar a própria comparação. 
a sugestão de que a universidade não é a única alternativa de educação, com a valorização do ensino profissional como opção preferencial para aqueles que não têm acesso ao curso superior, traz a marca dos projetos conservadores. Por fim, vale assinalar que, mesmo com as propostas de discriminação positiva, os currículos das universidades continuam a naturalizar a seleção de conteúdos, tidos como universais, num visível privilégio da tradição ligada ao lluminismo europeu (Valentim, 2005).

Em comparação às propostas conservadoras que criticam as políticas multiculturais, as abordagens tipificadas de forma genérica como liberais podem ser consideradas progressistas (McCarthy, 1994), mas ainda falham na resolução dos preconceitos contra a diferença. As teorias liberais são marcadas pela aceitação do caráter heterogêneo da sociedade e pela compreensão de que as identidades sociais são definidas tendo em conta indicadores econômicos, culturais e/ou biológicos. McLaren ( 1997) entende que há propostas multiculturais liberais cuja principal característica seria um certo humanismo, a crença em um princípio de igualdade entre as pessoas, independente, por exemplo, de raça e gênero. A diferença, para os humanistas liberais, seria ocasionada por condições desiguais do capitalismo, que fazem com que a competição social seja desfavorável a membros de grupos minoritários. No entanto, ainda que reconheçam a diferença, as propostas liberais compartilham com os conservadores uma postura universalista, caracterizando-se por uma tentativa de integração dos grupos culturais no padrão, baseado numa cidadania individual universal. As práticas particulares são aceitas, mas devem se limitar ao domínio privado. De forma geral, para os liberais, o culto à diferença ameaça o universalismo e a neutralidade do Estado, compromete a autonomia e a liberdade individual e ataca a igualdade formal. Ao contrário, defendem a necessidade de uma convivência pacífica entre os grupos diversos dentro de uma mesma nação (McCarthy, 1994). Afastam-se dos conservadores, no entanto, ao acreditarem na possibilidade de reversão das condições socioeconômicas que estariam na base da discriminação, especialmente com políticas integracionistas e compensatórias.

Para McCarthy (1994), as principais bases teóricas dos liberais são as teorias psicossociológicas e da privação cultural, a partir das quais explicam o fracasso das minorias nas escolas. $\bigcirc$ enfoque liberal é principalmente integracionista, propondo uma série de medidas para garantir a melhoria de acesso e 
permanência dessas minorias nas escolas. No geral, constituem-se em programas compensatórios ou em reformas curriculares, com inclusão da história, idioma e conquistas das minorias. No Brasil, recentemente, a Lei n. 10.639/ 2003 obrigou a inclusão no currículo escolar dos temas História e Cultura AfroBrasileira, além de História da África e dos africanos e a luta dos negros no Brasil, o que ainda não foi plenamente realizado. Na Universidade do Estado do Rio de Janeiro, a primeira do país a adotar o regime de cotas, praticamente todas as intervenções propostas no cotidiano da universidade para lidar com a nova situação se assentam na idéia da privação cultural. Foram criados cursos de recuperação em conteúdos básicos - língua e matemática - e ampliadas as ofertas culturais, como sessões de cinema, dentro de programas específicos para fazer frente à nova realidade. Políticas como essas reduzem as questões raciais a um problema de rendimento acadêmico das minorias e à disposição da escola de ajudar os alunos desses grupos. Dessa forma, a educação não é considerada como um lugar em que se produzem diferenças, sendo negligenciadas as relações entre escolarização e as dinâmicas de raça, gênero e classe.

Além do que tipifica como multiculturalismo liberal humanista, McLaren (1997) define uma versão de esquerda desse multiculturalismo, centrada no reconhecimento da diferença. Engloba as reivindicações de grupos minoritários por escolas especializadas nas quais suas culturas sejam valorizadas, proposta que recebe muitas críticas quando se trata de escolas para negros ou homossexuais, mas que é amplamente aceita quando se trata de grupos religiosos hegemônicos - escolas católicas e protestantes, por exemplo. Trata-se, segundo o autor, de uma solução que inverte as posturas conservadoras, mantendo a mesma lógica de um currículo monocultural e assentando-se na essencialização da diferença. De forma geral, o pertencimento a um grupo cultural é entendido como garantia de autenticidade, o que torna a experiência de vida do sujeito o fator primordial na construção de uma política de identidade. Embora também seja difícil hoje no Brasil encontrar projetos multiculturais deste tipo, alguns grupos étnicos os têm defendido. Para McLaren (1997), isso é um equívoco, na medida em que a experiência da diferença se dá em um cotidiano recheado de ideologia, afetos e conhecimentos. As conclusões de McCarthy (1994) sobre a assincronia das diferenças caminham no mesmo sentido do questionamento de uma identidade garantida por algum atributo essencial, seja ele 
biológico ou inclusive histórico. $\bigcirc$ autor demonstra, em uma série de exemplos, como as reivindicações de minorias de classe, raciais e de gênero podem ser antagônicas, em situações concretas. Nesse sentido, currículos centrados numa variante cultural não hegemônica não implicariam a formação de sujeitos com uma postura de defesa das culturas subalternas.

A tipologia de McCarthy (1994) inclui, para além dos projetos conservadores e liberais apresentados por McLaren ( 1997), a referência ao que denomina propriamente de projetos multiculturais. Trata-se de projetos que, dando conta da existência de diferentes culturas, buscam, de alguma forma, modos de regulá-la. Para o autor, foi o fracasso dos projetos liberais para lidar com a sociedade multicultural que levou ao surgimento das alternativas multiculturais, que podem ser subdivididas em três grandes discursos: da compreensão cultural, da competência cultural e do empoderamento cultural.

O discurso da compreensão cultural lastreia-se no relativismo cultural, na aceitação da diferença como algo positivo e no diálogo entre os diferentes grupos. Defende que os professores devem ser sensíveis às diferenças étnicas, buscando desenvolver atitudes positivas no que diz respeito a essas diferenças. No geral, assumem uma perspectiva benigna. No caso do Brasil, essa postura tem sido muito comum em propostas multiculturais ${ }^{2}$, tendo em vista especialmente a ideologia da miscigenação e da ausência de preconceitos raciais. Por ela, a nação brasileira foi constituída por diferentes etnias e essa diversidade é positiva na medida em que permitiu um desenvolvimento peculiar do país. A discriminação seria produto apenas de uma escola com currículos que não têm desenvolvido essa visão multicultural. A reversão dos preconceitos poderia ser atingida se as escolas assumissem uma visão mais positiva em relação à diversidade cultural. A meta desse tipo de proposta multicultural é a ausência de preconceitos, e por isso as atitudes dos sujeitos em relação a esses preconceitos desempenham um papel fundamental.

O discurso da competência cultural, por seu turno, advoga que o pluralismo cultural deve ocupar um lugar central nos currículos, com a definição de competências interculturais. Os programas mais comuns são os bilíngües,

2. Ver, por exemplo, o tema transversal Pluralidade Cultural dos Parâmetros Curriculares Nacionais. Análise desse documento foi realizada por Macedo (2006). 
biculturais e étnicos baseados em valores pluralistas. Os alunos devem desenvolver a identidade étnica, o conhecimento e a competência em diversos sistemas culturais. A educação intercultural pode ser um antídoto contra o preconceito, além de garantir a sobrevivência das culturas minoritárias. O objetivo é construir pontes entre as culturas. Essa opção privilegia uma mobilidade individual sobre uma política de identidade coletiva. No caso do Brasil, relevante trabalho no sentido de uma educação intercultural vem sendo desenvolvido por pesquisadores nucleados em torno de Candau, cujas atividades em educação e direitos humanos caminham no sentido do desenvolvimento de valores plurais. Nas palavras dessa autora,

...a educação na América Latina (...) somente assim poderá dar resposta aos desafios do continente: assumindo uma configuração plural, reconhecendo o conhecimento e as práticas educativas produzidas e acumuladas no continente, fazendo da escola um lugar de cruzamento de saberes e linguagens, de educação intercultural e construção de uma nova cidadania. (2000, p. 16)

Por fim, McCarthy ( 1994 ) identifica projetos vinculados aos discursos do empoderamento ou da emancipação cultural, centrados na história das minorias e na narrativa dos resultados que esses grupos vêm conquistando socialmente como instrumentos de favorecimento do sucesso escolar e econômico. Parte do princípio de que existe um desajuste entre o currículo e as experiências vividas pelas minorias, uma vez que as escolas privilegiam os valores da classe média branca. Dessa forma, a escola tem um papel importante na produção da diferença, sendo necessário pensar uma reforma que dê igualdade de oportunidades de êxito aos jovens das minorias. Para isso, o currículo precisa incluir a história e as conquistas dessas minorias. A preocupação com o empoderamento cultural tem estado presente, por exemplo, em muitas propostas educacionais ligadas aos subalternos e, no geral, por eles conduzidas, tais como os pré-vestibulares comunitários e as escolas ligadas tanto aos movimentos sociais quanto às reivindicações indígenas. Um dos problemas que McCarthy (1994) aponta em projetos desse tipo é que eles costumam assumir um tom otimista, passando por cima de relações sociais complexas que se estabelecem no interior da própria escola. Suas conclusões, a partir do estudo da realidade americana, é que trazer para os currículos materiais mais ligados 
às minorias não tem contribuído para diminuir a diferença nem no interior da escola nem na sociedade.

Essas tipologias certamente não dão conta do conjunto de possibilidades que o termo multiculturalismo vem assumindo. Poderíamos, por exemplo, como Hall (2003), falar ainda em uma variante comercial, que reconhece a diversidade dos indivíduos com o objetivo de resolver os problemas da diferença por intermédio do consumo privado; ou em multiculturalismo corporativo, em que as diferenças são administradas tendo em vista os interesses da maioria; ou de butique, privilegiando a comercialização e o consumo; ou mesmo o que é chamado de gerencialismo multicultural, cuja semelhança com o apartheid é salientada por Maharaj (apud Hall, 2003). Ainda que não esgotem as possibilidades de pensar os múltiplos projetos para lidar com uma sociedade multicultural, creio que esse panorama é suficiente para apresentar alguns indícios que me permitirão defender a necessidade de ir além de abordagens desse tipo, por vezes incorporando parte de suas preocupações.

Entendo que não há dúvidas de que os projetos que têm sido classificados como conservadores e liberais - por seu caráter monocultural, com o privilégio das culturas hegemônicas ou com o endeusamento de uma cultura "subalterna" - precisam ser vigilantemente banidos de nossas experiências ${ }^{3}$. Quanto às variantes que McCarthy denomina multiculturais, essa certeza necessita de argumentos que tento apresentar de forma mais orgânica. Como a maioria de nós defende, os projetos multiculturais buscam a solução das desigualdades, mas o fazem acreditando na "reversão de valores, atitudes e natureza humana dos atores entendidos como 'indivíduos'” (McCarthy, 1994, p.87).

No caso de projetos educativos, a escola ${ }^{4}$ e o currículo assumem papel de relevo nessa reversão. São projetos que apostam na necessidade de interação entre as culturas, diferenciando-se apenas parcialmente nas formas como entendem que essa interação precisa ser realizada. A despeito de suas especificidades, compartilham a idéia de adição ou substituição do que já está no currículo, seja na forma de novos conteúdos, seja de valores diferentes ou de

3. $\bigcirc$ que se torna mais difícil na medida em que muitas vezes não aparecem como projetos integrais, mas como características hibridizadas em outros tipos de projetos, tal como destaquei ao longo da seção.

4. Ou o lugar em que se dá o processo educativo. 
outras práticas pedagógicas. Essa adição somente se faz possível na medida em que as culturas são concebidas como repertórios partilhados de significados, fixos e homogêneos. Desses repertórios, caberia, então, selecionar um conjunto de práticas culturais a ser trabalhado pela escola, de modo que quanto mais plural fosse a seleção, mais representativo seria o currículo. Trata-se de uma postura que, certamente, garante mais visibilidade a culturas não européias, freqüentemente marginalizadas pelas sociedades ocidentais. Isso abre a possibilidade de construção de alianças políticas para viabilizar uma abordagem relacional que inclua os subalternos. No entanto, num mundo global, em que as relações de poder entre as culturas são francamente heterogêneas, não se pode falar em projetos multiculturais desse tipo sem questionar o lugar a ser ocupado pelas diferentes culturas nesse currículo plural. É possível uma interação entre culturas na escola que não reproduza os preconceitos através dos quais as culturas subalternas são vistas socialmente? Ou a interação promovida em projetos multiculturais seria apenas mais uma forma de dominação a que as culturas subalternas estariam submetidas? Em outros termos: é possível uma convivência entre culturas tendo em vista as relações de poder que permeiam sua própria existência?

\section{O DIÁLOGO OU A TRADUÇÃO ENTRE AS CULTURAS É MESMO POSSÍVEL?}

As respostas às questões formuladas acima não são simples. Se, por um lado, a interação entre as culturas é marcada por relações de poder desiguais, por outro, a aposta na incomensurabilidade entre as culturas põe em questão a função mesma da educação. Como indagam Burbules e Rice (1993), qual o sentido de um projeto educativo como espaço intersubjetivo por excelência se as culturas são incomensuráveis? Entendo que essa questão traduz um dos principais dilemas que o debate sobre a diferença apresenta à educação. $\mathrm{Na}$ maioria dos projetos multiculturais a interação entre as culturas é vista como uma somatória que, de forma um tanto quanto otimista, garantiria espaço para a convivência intercultural. Para além da idéia de somatório, diversos autores têm procurado tematizar a diferença cultural e pensar a articulação entre as culturas lançando mão de termos como diálogo (Burbules, Rice, 1993), tradução (Santos, 2005) ou solidariedade (Gilroy, 200I). 
Moreira (2002), em estudo no qual busca compreender como a discussão sobre multiculturalismo vem sendo incorporada ao campo do currículo, conclui que "a diferença e a crença no poder do diálogo para incrementar a compreensão entre as diferenças ocupam lugar de destaque nas falas e nas propostas pedagógicas de meus colegas" (p.2l). Diz ainda que a preocupação com o diálogo é mais forte para os autores que têm por objeto de estudo o multiculturalismo escolar do que para aqueles que se dedicam "mais à militância política, (...) para [quem] vale mais a especificidade e a intensidade de cada luta que o diálogo entre os diferentes grupos" (p.2l). Embora a divisão dos teóricos em dois grupos seja questionável, ela explicita a tensão entre a idéia de que as culturas são incomensuráveis e a necessidade, sentida por alguns, de pensar formas de estabelecer uma ponte entre elas.

Assumo a idéia da incomensurabilidade entre as culturas, idéia que defenderei contrapondo-me às noções de tradução, tal como explicitada por Santos (2005), e de diálogo comunicativo como formulado por Burbules e Rice (1993). Fujo, porém, das teorizações de autores que apostam mais radicalmente na fragmentação, entendendo que a interação entre as culturas é necessária, mas deve ser pensada não como somatório ou equivalência (tradução) entre repertórios de sentidos partilhados, mas como algo que se dá entre culturas como espaço de enunciação.

Tal como salientado por Moreira (2002), a idéia de diálogo comunicativo é talvez a mais forte referência para autores que advogam a necessidade de criação de experiências interculturais na escola e no currículo. Em texto datado de 1991, Burbules e Rice (1993) defendiam a necessidade de diálogo intercultural, numa proposta fortemente influenciada pela teoria da ação comunicativa de J. Habermas. Nesse sentido, aceitavam que a comunicação livre de constrangimentos, embora impossível de se materializar em contextos específicos, devia ser o pressuposto de todo diálogo comunicativo. Sustentavam, assim, a idéia de uma razão universal, apesar das diferenças, voltada para a necessidade de comunicação e de consenso.

Os autores acreditavam que o diálogo comunicativo seria capaz de constituir identidades mais flexíveis e menos arbitrárias, de ampliar a compreensão do outro e do próprio eu e de estabelecer "virtudes comunicativas", dentre as quais a tolerância e o respeito às diferenças. Propunham, então, a criação de redes intersubjetivas tanto para criar significados comuns quanto para viabilizar 
"a compreensão, a tolerância e o respeito entre as diferenças" (p. 194). Neste último sentido, os autores pensaram no diálogo como forma de permitir que as diferenças entrassem em contato, sem que necessariamente se chegasse a um acordo sobre as crenças e os valores a propósito dos quais se daria esse diálogo. Seria possível um diálogo que não implicasse um acordo, mas em que se respeitassem as posições discordantes. E que permitisse o desenvolvimento de virtudes comunicativas para expressar uma "atitude afetiva e intelectual" com relação ao outro, uma disponibilidade que seria posta em ação em situações contextuais específicas 5 .

Burbules e Rice (1993) tentaram fugir dos problemas representados pela distribuição desigual de poder entre as culturas, defendendo o diálogo como estratégia. Assim, o produto da relação dialógica - o entendimento, fortemente influenciado pelas relações de poder - seria menos importante que o diálogo mantido, que criaria a possibilidade de desenvolvimento de capacidades para o diálogo. No entanto, essa posição de Burbules e Rice é fortemente criticada por Ellsworth (1997), com o argumento de que os limites da continuidade do diálogo não são estabelecidos, o que torna impossível perceber, por exemplo, o lugar do inconsciente - com toda a sua descontinuidade - nas interações. Assim, o diálogo acaba por assumir um papel quase místico mediante o qual o entendimento se torna possível. Para a autora, ainda que fosse possível suprimir as relações de poder no convencimento sobre as posições em diálogo, elas se explicitariam na própria obrigatoriedade do diálogo. Uma obrigatoriedade que se estabelece pela excessiva positividade de que o diálogo é revestido, sempre associado à democracia e ao pluralismo. A ênfase na participação universal, que Burbules e Rice simplesmente apagam, subjaz a essa mistificação, não intencional, da idéia de diálogo.

A argumentação de Ellsworth põe em questão a validade do próprio diálogo, denunciando o quanto sua obrigatoriedade conduz a um processo de exclusão. Apoiada na noção de modos de endereçamento, que traz do cinema, a autora considera que o discurso da participação universal controla a posição de sujeito que será assumida pelo "outro". É nesse controle que resi-

5. Poderíamos dizer que uma posição semelhante é encontrada na noção de diálogo defendida por Paulo Freire. 
de o poder que Burbules e Rice não percebem, o poder de definir quem é o "outro". Um "outro" que pode participar do diálogo ou que será o sujeito de todos os vícios, aquele que desdenha a democracia. Nesse sentido, o diálogo universal nada tem de universal, posto que repousa em uma exclusão. E o diálogo plural não é capaz de, como apregoa, excluir a exclusão. Não se trata de um convite, mas de uma obrigatoriedade ao diálogo. Mesmo que, como argumentam Burbules e Rice, o diálogo pudesse redundar em respeito às posições discordantes, essa discordância não inclui a opção pela não participação. Nas palavras de Ellsworth ( 1997 ), o que "o diálogo comunicativo não pode tolerar, o que ele tem que excluir, é aquele que diz: 'nossas diferenças são tamanhas que você não pode me entender e eu não posso entendê-lo'. Isso rompe a possibilidade do diálogo" (p. 107).

Para os autores que acreditam na necessidade de uma ponte entre as culturas, a idéia de tradução está muito presente, ao lado da noção de diálogo comunicativo. Entre os trabalhos que defendem a tradução intercultural destacam-se, pela importância crucial que vêm adquirindo na discussão da diferença no Brasil, os estudos de Santos (200 I, 2003, 2005) . O autor defende a articulação das diferenças na construção de um projeto alternativo contra-hegemônico, articulação que repousa na crença da possibilidade de tradução entre repertórios culturais diferentes. A noção de tradução é, para Santos (2005), uma alternativa às formas como a Modernidade lidou com as diferenças - criando uma teoria geral -, e também ao capitalismo global, ao neoliberalismo ou ao que denominaríamos lógica mercantil. $\bigcirc$ autor assume que a diversidade de culturas é uma realidade antiga que, tendo sido resolvida pela Modernidade com a alusão a noções como totalidade e teleologia, irrompe hoje como fragmentação e ausência de sentido de transformação social. Ainda que se preocupe com estas manifestações contemporâneas, defende que as respostas modernas foram igualmente problemáticas, na medida em que desperdiçaram experiências plurais e ricas que não cabiam nas totalidades construídas. Assim, adota uma posição muito própria, discordando das correntes que denomina pósmodernas celebratórias, que não vêem problemas na fragmentação e na au-

6. Santos é citado por Candau (2005), Moreira (2002), Moreira e Macedo (2002), Moreira e Canen (200I), entre outros. 
sência de sentido para a transformação social, mas, ao mesmo tempo, aceitaas como descrição da contemporaneidade. A proposta de Santos (2005) para lidar com o dilema contemporâneo tal como o apresenta é a instauração de uma razão cosmopolita, que se proponha "novas formas de pensar [as] totalidades e de conceber [seus] sentidos" (p.80 I). Uma razão que viabilizaria "uma justiça cognitiva global”, necessária a uma "justiça social global” (p.8|3).

A razão cosmopolita centra-se em um trabalho de tradução que deve ser levado a cabo por intelectuais cosmopolitas, ou seja, sujeitos enraizados nas práticas e saberes de seus grupos. A tradução seria, portanto, "o procedimento que permite criar inteligibilidade recíproca entre as experiências de mundo. (...) Trata-se de um procedimento que não atribui a nenhum conjunto de experiências nem o estatuto de totalidade exclusiva, nem o estatuto de parte homogênea" (Santos, p.802). Poderia se envolver saberes, na forma de uma hermenêutica diatópica, ou práticas sociais e seus agentes.

Na perspectiva dos saberes, a tradução consistiria em identificar preocupações aparentemente semelhantes entre as culturas e as respostas que cada uma constrói. Está na base dessa proposta a idéia de que o diálogo entre as culturas não apenas é possível, mas capaz de ampliar as compreensões propiciadas por cada cultura pelo confronto entre posições divergentes. Todas as culturas são tidas como incompletas - universalismo negativo -, e a idéia de uma cultura universal é creditada ao fato de uma particularidade ocidental ter sido erigida como universal. No que diz respeito às práticas sociais, Santos (2005) defende que a tradução objetiva "criar inteligibilidade recíproca entre formas de organização e entre objectivos de acção" (p.805). Trata-se de uma preocupação com os saberes aplicados que se torna mais evidente quando as práticas são mais diversificadas do que os saberes que as informam. De forma análoga à tradução dos saberes, a tradução das práticas busca determinar o que aproxima e afasta os diferentes movimentos. Dado que a tradução pode se realizar tanto entre a cultura hegemônica e as subalternas quanto entre estas últimas, cria-se um espaço de articulação entre saberes e práticas subalternas relevante para a construção de uma contra-hegemonia.

No campo das políticas culturais, a noção de tradução de Santos (2005) assenta-se na idéia de um consenso transcultural, que é tanto mais complexa na medida em que as culturas em si também não são homogêneas. Para o autor, as culturas estão sempre em contato umas com as outras, criando zonas de 
contato, regiões de fronteira. São, portanto, híbridas. As relações que se estabelecem nessas zonas são variadas, indo de relações coloniais a práticas de tradução cosmopolitas. Nestas práticas, defende Santos, cada cultura define e redefine continuamente - o que deve ser posto em contato, numa seleção que não é apenas ativa, mas também passiva. A seleção passiva é constituída fundamentalmente das ausências, algumas delas profundas, ocasionadas por formas diversas de opressões. As traduções que Santos destaca por seu potencial de transgressão são fundamentalmente as baseadas em experiências de carência que precisam ser superadas. Experiências de construção de outras zonas de contato em substituição às zonas coloniais observadas entre culturas hegemônicas e subalternas. Experiências que são o "resultado de uma conjugação de tempos, ritmos e oportunidades" ( $p .8$ I l) exercidas pelos diferentes grupos sociais.

Ainda que Santos dê conta do hibridismo que caracteriza os contatos entre as culturas, percebendo a dinâmica que ocorre em zonas de fronteira cultural, seu trabalho de tradução é entendido como um trabalho argumentativo. Essa característica traz algumas dificuldades para a idéia de tradução, especialmente no que tange aos aspectos normativos que guiam o trabalho na zona de contato, muitas delas elencadas pelo próprio autor. Nessas zonas de contato onde se dá a tradução, é necessário um consenso básico válido sobre premissas argumentativas, o que nos põe diante de questões de poder como as que foram levantadas na discussão sobre a idéia de diálogo. Porém, mais sérias ainda, são as dificuldades criadas pela percepção de que nem que todos os saberes e práticas são pronunciáveis em todas as línguas. Também os silêncios que as constituem e alteram os sentidos do que é dito têm significados diferentes em culturas e línguas diversas. Essas dificuldades, especialmente no que se refere à linguagem, não são tratadas com profundidade por Santos e entendo que, apenas por isso, o autor pode defender uma proposta de tradução entre culturas. Sustento que essas dificuldades dão conta de uma incomensurabilidade entre as línguas e entre as culturas, que por si só inviabilizaria a experiência da tradução tal como apresentada pelo autor.

As críticas que procurei levantar às posturas que defendem a possibilidade de algum tipo de equivalência entre as culturas - que viabilizariam tanto o diálogo comunicativo quanto a tradução como trabalho argumentativo - trazem a necessidade de pensar outras alternativas para essa interação. Noções 
como diálogo e tradução repousam sobre premissas de similaridade e diferença como instâncias relacionadas entre si. Necessitam que as diferenças sejam definidas tendo por base um padrão comum. Assim, as possibilidades tanto da tradução (Santos, 2005) quanto do diálogo comunicativo (Burbules, Rice, 1993) acabam por reeditar, de alguma forma, a idéia de pluralismo, que sustenta também os projetos multiculturais. Fundamentam-se num tipo de pluralismo que, segundo Burbules ${ }^{7}$ (2003), "considera as diferenças como suplemento" (p. I 80). De forma diversa e me apropriando das palavras do próprio Burbules, entendo que é necessária uma gramática da diferença, que explicite, sem essencializar, as diferenças, realçando-as em contextos em que elas não parecem significativas. Uma gramática na qual os sistemas em que se estabelecem as diferenças são postos em questão. Buscarei defender uma tal gramática valendo-me da idéia de que a cultura é um espaço de enunciação, e não apenas um repertório partilhado de significados (Bhabha, 2003). Isso implica que a cultura seja vista como uma relação hegemônica.

\section{SE AS CULTURAS SÃO INCOMENSURÁVEIS, QUAL O LUGAR DA EDUCAÇÃO?}

A incomensurabilidade e intraduzibilidade das culturas podem redundar em descrições de tal modo fragmentadas que não se pode sequer falar de mediações entre as culturas particulares. Paradoxalmente, numa tal posição, o que sai de cena são as culturas particulares, na medida em que se fecham em si mesmas e assumem o papel de totalidades constituídas em relação de oposição a outras totalidades. Essa ausência de mediação - além da clássica mediação estruturalista entre igualdade/diferença - acaba por impedir a tematização da diferença como "diferença além", "no interior" e "contra" (Burbules, 2003), restringindo-a a uma espécie de diversidade. Com isso, chego ao argumento central deste texto, qual seja, a necessidade - para que a educação tenha uma razão de ser como projeto - de uma negociação de sentidos entre as culturas

7. Burbules, em texto posterior ao analisado neste trabalho, publicado no Brasil em 2003, passa a considerar o diálogo comunicativo como uma impossibilidade e a defender a incomensurabilidade entre as culturas. 
particulares, uma negociação que será sempre política e que está na base dos processos democráticos.

Ainda que as posturas conservadoras e liberais quanto à forma como se deve tratar a diferença na escola estejam presentes em práticas curriculares cotidianas, creio que podemos afirmar que uma perspectiva essencial da diferença está sendo superada. De forma geral, os princípios do estruturalismo trouxeram ao centro da cena a idéia de que os processos de produção de sentido dependem da linguagem e de que a diferença é sempre um processo relacional. Assim, uma cultura particular só existiria em função de uma outra que se diferencia dela, não possuindo nenhuma característica interna que lhe dê identidade. Essa visão não impede, no entanto, que as identidades culturais, assim como as diferenças entre elas, sejam fixadas num processo cujos efeitos políticos se assemelham aos da essencialização. As referências que permitem tal fixação são mitos fundadores, constituídos por uma certa fidelidade às origens, às histórias comuns, à tradição. Ainda que mudem os marcos da identidade - da biologia para a história e a tradição - a concepção binária da diferença permanece, possibilitando a construção do eu e do outro a partir de uma oposição rígida entre o que está e o que não está incluído. Como ressalta Hall (2003), "a diferença cultural de um tipo rígido, etnicizado e inegociável substituiu a miscigenação sexual enquanto fantasia pós-colonial primordial" (p.46). Projetos multiculturais que lidam com a cultura de forma orgânica, tratando os diferentes pertencimentos como experiências coletivas unitárias, não são incomuns. No campo educacional, a conceitualização da cultura como repertório ou acervo de significados a serem manipulados ainda está muito presente em propostas curriculares, mesmo quando explicitam preocupação com a diferença ${ }^{8}$. Freqüentemente, a cultura é pensada como algo externo à situação pedagógica de onde se deve tirar "os conteúdos" que serão trabalhados por um currículo inter/multicultural. Mesmo se contrapondo aos princípios universalistas da nação ou mesmo do lluminismo, acabam por estabelecer culturas particulares como totalidades.

8. Em textos anteriores abordei essa característica tanto em propostas curriculares, como os Parâmetros Curriculares Nacionais - PCN (Macedo, 2006), quanto na produção teórica do campo do currículo (Macedo, 2004a). 
Apóio-me em Bhabha (2003) para tentar entender, de um lado, os mecanismos utilizados por essas culturas para se perceberem de forma holística, em contraposição aos "outros" culturais e, de outro lado, a ambivalência sempre presente nesse processo. De acordo com o autor, poderíamos falar de uma cultura ${ }^{9}$ imaginada, de certa forma orgânica, marcada por uma temporalidade continuista que tira seus sentidos da história. É o que poderíamos denominar dimensão pedagógica da cultura, dimensão que tende para a totalização homogeneizante e cuja força no imaginário educacional nos ajuda a entender a noção reificada de cultura que predomina explicitamente em projetos inter/ multiculturais. Uma reificação que fixa os sentidos da cultura nas tradições de um passado e implica na submissão da diferença à diversidade. Diversidade que, para Bhabha (2003), pode ser descrita como "o reconhecimento de conteúdos e costumes culturais pré-dados; mantida em um enquadramento temporal relativista, ela dá origem a noções liberais de multiculturalismo, de intercâmbio cultural ou da cultura da humanidade" (p.63). Trata-se, portanto, de uma perspectiva que, mesmo não sendo essencial no sentido clássico do termo associado à biologia ou à metafísica -, fixa e distorce a diferença.

Quero salientar, no entanto, a ambivalência entre essa dimensão pedagógica e uma temporalidade performática da cultura, uma temporalidade que nega qualquer temporalidade anterior, qualquer referência a um passado essencialmente bom que seria a sua própria negação. A temporalidade performática introduz na coesão proposta por teorias orgânicas da cultura e da comunidade - em que até mesmo gênero, classe, sexualidade são vistos como experiências coletivas unitárias - um elemento perturbador. A tensão entre repetição e performatividade cria uma zona de ambivalência, um espaço-tempo liminar que possibilita que a cultura se estabeleça como um lugar de enunciação onde a diferença cultural se constitui. $\bigcirc$ outro cultural que surge na temporalidade performática não é o negativo da cultura legitimada, mais um a ser somado às culturas já vistas na constituição de uma sociedade plural. Para Bhabha (2003), falar em cultura como lugar de enunciação é pensar em um

9. Bhabha (2003) trabalha a ambivalência dos conceitos de nação e de povo e não propriamente de cultura. No entanto, como define a nação ocidental como uma "forma obscura e ubíqua de viver a localidade da cultura" (p. 199), julgo possível utilizar os argumentos do autor para tratar a cultura. 
entre-lugar onde as vozes marginais "não mais necessitem dirigir suas estratégias de oposição para um horizonte de 'hegemonia', que é concebido como horizontal e homogêneo" (p.2।3). Ao contrário, o autor fala de uma luta que se dá entre "o tempo e a narrativa historicistas, teleológicos ou míticos do tradicionalismo - de direita e de esquerda - e o tempo deslizante, estrategicamente deslocado, da articulação de uma política histórica de negociação" (p.64).

$\mathrm{Na}$ cisão entre uma temporalidade pedagógica e outra performática, que estabelece a cultura como lugar de enunciação, as identidades são sempre forjadas num terreno movediço, em entre-lugares culturais, híbridos e complexos. Não podem ser concebidas com base numa oposição entre presença e ausência absolutas, como proposto pelo estruturalismo ${ }^{10}$. Na perspectiva aberta por Bhabha (2003), seria mais produtivo pensar na diferença como define Derrida (199|) no que denomina différance. Como no estruturalismo, a cultura é vista como um processo de atribuição de significados, significados estes que dependem de um sistema de diferenças. No entanto, na perspectiva pósestruturalista de Derrida, tais significados não podem ser fixados de forma decisiva. Ainda que se mantenha a fantasia de um significado fixo, cabal, ele nunca será totalmente apreensível. Ao invés de oposições binárias fixas, a différance introduz a incerteza que põe em interação as relações entre as culturas e os espaços que as distinguem, tornando a identificação dos sujeitos com determinadas culturas um processo ativo e contingente. Assim, o que muitas vezes denominamos diferença entre culturas vistas como repertórios partilhados de significados nada mais é do que um retrato cristalizado de um momento particular. Nesse sentido, quando, por exemplo, as políticas de ação afirmativas são questionadas por uma suposta dificuldade de definição racial no Brasil, o que está em jogo é uma atribuição externa de um epíteto racial aos sujeitos. Se analisada da perspectiva da différance, essa crítica não se sustenta, pois o processo de identificação do sujeito com o grupo tem uma dimensão subjetiva e ativa.

10. Na literatura sobre currículo, a idéia de que o outro é definido com base na oposição presença/ausência é apontada com alguma freqüência como definidora de posturas pós-estruturalistas, o que segundo Peters (2000), é um equívoco comum na análise do estruturalismo e do pós-estruturalismo. A indistinção por vezes presente no campo do currículo dificulta a tematização da diferença, aproximando-a da noção de diversidade ou pluralismo. 
A partir dessa noção de différance, Bhabha (2003) fala de um tipo de tradução ou de negociação da diferença, como forma de subversão (Hall, 2003), que se distancia da tradução como explicitada por Santos (2005) e de propostas de diálogo comunicativo". Trata-se de uma temporalidade em que elementos antagônicos e até mesmo contraditórios se articulam sem a perspectiva da superação. Essa negociação cria espaços de luta híbridos, nos quais polaridades positivas ou negativas, ainda que relativas, não se justificam. Ou seja, na temporalidade da negociação com a qual trabalha Bhabha (2003), não é possível pensar em sentidos fixos, primordiais, que reflitam objetos políticos unitários e homogêneos. Categorias que têm alicerçado muitas de nossas lutas políticas - tais como negros, mulheres, gays, trabalhadores - só ganham sentido nos discursos que as constroem e, portanto, existem na tensão histórica, em que negociam espaço. Assim, elas próprias são um processo de tradução. Rearticulam os elementos que supostamente as constituem, contestando os territórios que cada uma definiu para si. Nas palavras de Bhabha (2003), "cada formação [identitária] enfrenta as fronteiras deslocadas e diferenciadas de sua representação como grupo e os lugares enunciativos nos quais os limites e limitações do poder social são confrontados em uma relação agonística" (p.55). Ao sustentar que essas categorias não implicam posições fixadas num espectro político claro, o autor não está propondo o fim da atuação política, mas a necessidade de se elaborar alternativas - políticas e teóricas - para um mundo contemporâneo marcado pela ambivalência dos pertencimentos identitários. Um mundo em que as formas divisionárias de identificação parecem mais fortes do que as solidárias.

Mas, como pensar essa ação política? Que relações ela estabeleceria com os muitos projetos - conservadores, liberais ou multiculturais - em curso? Imagino que para dar uma resposta, ainda que provisória, a questões deste tipo é necessário revisar, como fazem Hall (2003), Bhabha (2003) e Laclau e Mouffe

| I. A noção de tradução utilizada por Bhabha é um processo de construção de significado que envolve uma interação entre as culturas. Como define Maharaj (apud, Hall, 2003), com base em Derrida, "o tradutor é obrigado a construir o significado na língua original e depois imaginálo e modelá-lo uma segunda vez nas matérias da língua com a qual ele ou ela o está transmitindo. As lealdades do tradutor são assim divididas e partidas" (p.4I). Nessa perspectiva, não fariam sentido as dificuldades levantadas por Santos (2005) para a tarefa de tradução, tendo em vista que ela só é possível como processo de hibridação. 
(200 I), a noção de hegemonia, entendida como categoria central das análises políticas. Apresento a questão tal como formulada por Bhabha, pois entendo que ela dá conta dos dilemas contemporâneos enfrentados pelos movimentos sociais:

...poderão esses sujeitos divididos e esses movimentos sociais diferenciados, que mostram formas ambivalentes e divididas de identificação, serem representados em uma vontade coletiva em que ecoa claramente a herança iluminista de Gramsci e seu racionalismo? (2003, p.57)

Para Bhabha (2003), a hegemonia precisa ser pensada como um "processo de iteração e diferença", no qual imagens diferentes vivem em antagonismo com outras, tendo, portanto, uma "presença parcial". Dessa forma, a hegemonia não pode, segundo o autor, ser entendida como "imagem da vontade coletiva" (p.56). Tendo por horizonte epistemológico o pós-estruturalismo, e apoiando-se nos conceitos de desconstrução e de ponto nodal, Laclau e Mouffe (200l) suscitam uma discussão da noção de hegemonia que, a meu ver, ajuda a pensar a questão tal como formulada por Bhabha.

Para Laclau e Mouffe, toda relação hegemônica assume, uma dimensão universalista, porém, é necessário reconceitualizar o sentido de universal, tendo em vista os sentidos que ele assumiu ao longo da história do pensamento ocidental. Para o autor, esse sentido "resulta (...) de uma dialética específica entre o que chamamos de lógicas da diferença e lógicas da equivalência” (p.xiii). De forma genérica, poderíamos dizer que toda cultura, ou mesmo todos os sujeitos, assumem um lugar social particular, o que implicaria a inexistência de totalidades, e redundaria não apenas na incomensurabilidade entre as culturas, mas na não-interação entre elas. Nessa perspectiva, não haveria particular, porque todo particular estaria fechado em si e se configuraria como uma totalidade. Ocorre que antagonismos sociais criam cadeias de equivalências entre particulares, o que poderia ser aproximado da noção de solidariedade formulada por Gilroy ${ }^{12}$ (200 I). No entanto, essa cadeia de equivalentes precisa assumir uma representação que transcende as particularidades, o que é realiza-

12. Entendo que a idéia de zonas de contato apresentada por Santos (2005) poderia ser pensada nessa perspectiva; no entanto, sua defesa da tradução como trabalho argumentativo reinstaura, em seu texto, uma perspectiva universal da razão que o distancia dessa abordagem. 
do quando uma particularidade assume a função universal'3. É o que Laclau e Mouffe (200l) caracterizam como uma relação hegemônica.

Assim, toda universalidade é contingente e reversível. Trata-se de um conceito político e, portanto, dependente das relações de força que se dão dentro das sociedades, que o autor denomina antagonismos sociais. Esses antagonismos são entendidos "não como relações objetivas, mas como relações que revelam os limites da objetividade" (p.xiv). Nesse sentido, a discussão de Laclau afasta-se da idéia de diálogo, do que ele chama de "sacralização do consenso" (p.xv) em que se movem muitos dos projetos políticos multiculturais. Toda negociação envolve, para o autor, uma relação hegemônica que impede sua total realização, o que é característico do projeto democrático. Na perspectiva de hegemonia defendida por Laclau e Mouffe (200 I), os pertencimentos identitários mantêm a ambivalência de que fala Bhabha (2003). Ao mesmo tempo em que defendem que as diferentes culturas são incomensuráveis, os autores se negam a aceitar algumas descrições pós-modernas em que as particularidades se somam umas às outras sem nenhum tipo de mediação. A mediação, no entanto, não é estabelecida por nenhum princípio transcendente - como a vontade coletiva, por exemplo -, mas por decisões contingentes, que denominam hegemônicas.

As discussões de Bhabha e um conceito contingente de hegemonia propiciam uma nova forma de ver a ação política. Uma forma que difere tanto de propostas multiculturais em curso - que se alicerçam em uma mudança das atitudes dos sujeitos - , quanto de posturas iluministas que personificam a resistência em um intelectual crítico, transformador ou cosmopolita. Ao invés de posições claramente definidas do tipo "o poder" e "a resistência", a ação política pós-colonial de Bhabha se centra na "negociação na prática" (Hall, 2003, p.87), sempre agonística. Uma ação contingente levada a cabo por sujeitos que se definem "não como marginais, figuras de proa, profissionais ou acadêmicos atuando sozinhos, mas como cidadãos críticos cujo conhecimento coletivo e as ações pressupõem visões específicas da vida pública, da comunidade e do compromisso moral" (Giroux, 200 I, p. 19).

13. Aqui os autores se apropriam do conceito de ponto nodal, de Lacan, defendendo que toda cultura particular pode assumir uma função universal, sem que nenhuma característica própria dessa cultura seja a responsável por isso. Trata-se de um processo de identificação, que torna possíveis transições hegemônicas dependentes do processo político. 
Parece-me central, no entanto, num tempo dominado por discursos globais e homogêneos, por hegemonias que não se admitem transitórias, deixar claro que o "negociar na prática" ou o negociar-com-a-diferença exige mobilização política. A argumentação de Bhabha (2003) de que toda cultura é híbrida e de que não há, na interação entre culturas, a possibilidade de imposição absoluta (Macedo, 2004) não implica a desconsideração de estratégias que visam à manutenção do poder colonial. Ainda que não seja absoluto, e apenas por isso possa ser combatido, o poder colonial exige de nós uma articulação estratégica dos saberes de diferentes grupos culturais sem que isso implique a contestação da singularidade da diferença. Como alerta o autor (2003), o poder colonial não pode ser desprezado em suas tentativas de aniquilação das culturas subalternas, com suas estratégias de estereotipar a diferença para reduzi-la ao mesmo essencializado. Uma redução que busca controlar a ambivalência da dominação, dificultando a luta subalterna. Contudo, é também verdade que essa dominação, por sua própria natureza híbrida, cria regiões de fronteira em que se torna obrigatório negociar o inegociável, e é nessa região que reside nossa esperança de construção de uma política da diferença. É claro que não se trata de uma resistência capaz de surgir do nada, mas de um processo que pode ser construído por aqueles que habitam na fronteira entre diferentes identidades culturais e são capazes de traduzir "as diferenças entre elas numa espécie de solidariedade” (Bhabha, 2003, p.238). Uma agência póscolonial necessita, como qualquer outra, de uma fundamentação, mas não podemos esperar construir uma fundamentação totalizada sob pena de estarmos quebrando o jogo hegemônico necessário a um processo político democrático e realmente plural.

\section{REFERÊNCIAS BIBLIOGRÁFICAS}

BAUMAN, Z. Identidade. Rio de Janeiro: Zahar, 2005.

BHABHA, H. O Local da cultura. Belo Horizonte: UFMG, 2003.

BRASIL. Leis e decretos. Lei n. 10.639, de 9 de janeiro de 2003: altera a Lei n. 9.394, de 20 de dezembro de 1996, que estabelece as diretrizes e bases da educação nacional, para incluir no currículo oficial da rede de ensino a obrigatoriedade da temática "História e Cultura Afro-Brasileira", e dá outras providências. Brasília, 2003. 
BURBULES, N. Uma gramática da diferença: algumas formas de repensar a diferença e a diversidade como tópicos educacionais. In: GARCIA, R. L.; MOREIRA, A. F. B. (orgs.) Currículo na contemporaneidade: incertezas e desafios. São Paulo: Cortez, 2003. p. I 59- 188.

BURBULES, N.; RICE, S. Diálogo entre as diferenças: continuando a conversação. In: SILVA, T. T. (org.) Teoria educacional crítica em tempos pós-modernos. Porto Alegre: Artes Médicas, 1993. p. 173-204.

CANDAU, V. M. Culturas e educação: entre o crítico e o pós-crítico. Rio de Janeiro: DP\&A, 2005. Sociedade multicultural e educação: tensões e desafios, p. I3-38.

CHATERJEE, P. Comunidade imaginada por quem? In: BALAKRISHNAN, G. (org.) Um mapa da questão nacional. Rio de Janeiro: Contraponto, 2000. p.227-238.

DERRIDA, J. Margens da filosofia. Campinas: Papirus, 1991.

ELLSWORTH, E. Teaching positions: difference, pedagogy and the power of address. New York: Teachers College Press, 1997.

Why does this feel empowering? Working through the repressive myths of critical pedagogy. Havard Educational Review. Cambrigde, v.59, n.3, p.297-324, 1989.

GIROUX, H. Cultural studies as performative politics. Cultura/Studies. Critica/Methodologies, v. I, n. I, p.5-23, fev. 2001 .

GILROY, P. Atlântico negro. São Paulo: Editora 34; Rio de Janeiro: Universidade Cândido Mendes, 200I.

GRUNDY, S. Curriculum: product or praxis. New York: RoutledgeFalmer, 1987.

GUIMARÃES, A. S. A. Contexto histórico-ideológico do desenvolvimento das ações afirmativas no Brasil. In: SEMINÁRIO INTERNACIONAL AÇÕES AFIRMATIVAS NAS POLÍTICAS EDUCACIONAIS BRASILEIRAS: o contexto pós-Durban. Brasília: Ministério da Educação, Câmara Federal, 20-22 set.2005. Disponível em: www.fflch.usp.br/sociologia/asag/. Acesso em: jan. 2006.

HALL, S. Da diáspora: identidades e mediações culturais. Belo Horizonte: UFMG, 2003.

LACLAU, E. Emancipación y diferencia. Buenos Aires: Difel, 1996.

LACLAU, E.; MOUFFE, C. Hegemony and socialist strategy. Londres: Verso, 2001 .

MACEDO, E. Ciência, tecnologia e desenvolvimento: uma visão cultural do currículo de ciências. In: LOPES, A. C.; MACEDO, E. (orgs.) Currículo de ciências em debate. Campinas: Papirus, 2004. p. II9- 152.

Currículo como espaço-tempo cultural. In: REUNIÃO ANUAL DAANPED, 27. Anais. Rio de Janeiro: DP\&A, 2004a. p. I- 12. (CD-Rom) 
Currículo e diferença nos parâmetros curriculares nacionais. In: LOPES, A. C.; MACEDO, E.; ALVES, M. P. C. (orgs.) Cultura e política de currículo. Araraquara: Junqueira \& Marin Editores, 2006. p. |39-| 18.

MCCARTHY, C. Racismo y curriculum. Madrid: Morata; La Coruña: Fundación Paidéia, 1994. McLAREN, P. Multiculturalismo crítico. São Paulo: Cortez, 1997.

MOREIRA, A. F. B. Currículo, diferença cultural e diálogo. Educação e Sociedade, Campinas, v.23, n.79, p. 15-38, ago. 2002.

Currículo: políticas e práticas. Campinas: Papirus, 1999. Multiculturalismo, currículo e formação de professores, p.81-96.

MOREIRA, A. F. B.; CANEN, A. Ênfases e omissões no currículo. Campinas: Papirus, 2001. Reflexões sobre multiculturalismo na escola e na formação docente, p. 15-44.

MOREIRA, A. F. B.; MACEDO, E. Currículo, práticas pedagógicas e identidades. Porto: Porto Editora, 2002. Currículo, identidade e diferença, p. I I-34.

PETERS, M. Pós-estruturalismo e filosofia da diferença. Belo Horizonte: Autêntica, 2000.

SANTOS, B. de S. Conhecimento prudente para uma vida decente: um discurso sobre as ciências revisitado. São Paulo: Cortez, 2005.

A Crítica da razão indolente. São Paulo: Cortez, 2001.

Pela mão de Alice. São Paulo: Cortez, 1997.

(org.) Reconhecer para libertar. os caminhos do cosmopolitismo cultural.

São Paulo: Cortez, 2003.

SANTOS, B. de S.; NUNES, J. A. Introdução: para ampliar o cânone do reconhecimento, da diferença e da igualdade. In: SANTOS, B. de S. (org.) Reconhecer para libertar. os caminhos do cosmopolitismo cultural. São Paulo: Cortez, 2003. p. 25-59.

SPIVAK, G. Quem reivindica a alteridade. In: HOLANDA, H. B. (org.) Tendências e impasses. o feminismo como crítica da cultura. Rio de Janeiro: Rocco, 1994. p. I 87-205.

VALENTIM, D. Políticas de ação afirmativa e ensino superior a experiência da Uerj na perspectiva dos professores da Faculdade de Direito. Rio de Janeiro, 2005. Dissert. (mestr.) PUC-RJ.

Recebido em: fevereiro 2006

Aprovado para publicação em: março 2006 